\title{
Reducing donor exposure in preterm infants requiring multiple blood transfusions
} Anna Wood, Nicholas Wilson, Patricia Skacel, Roslyn Thomas, Elizabeth Tidmarsh,
Christopher Yale, Mahes de Silva

\begin{abstract}
Preterm infants frequently require multiple blood transfusions. Traditionally, 'fresh' (less than seven days old) blood has been used but this often results in transfusions from multiple donors. To reduce donor exposure the policy for top-up transfusions was changed. A unit of blood under five days old with additional satellite packs was ordered for each infant and used up to its expiry date, allowing up to eight transfusions from a single donation to be given. The mean (SD) number of transfusions per infant in 43 infants transfused according to previous policy and in 29 transfused according to the new policy was similar at $5 \cdot 6(4 \cdot 0)$ and $5 \cdot 3(3 \cdot 1)$, respectively. However, donor exposure fell following the change in policy from $4.9(3.5)$ to only $2.0(0.9)$. Only one infant was exposed to more than three donors compared with 24 infants in the control group. Plasma potassium concentrations were not significantly different following transfusion of blood stored for up to 33 days.
\end{abstract}

This simple change in policy has reduced donor exposure in infants requiring multiple top-up transfusions.

(Arch Dis Child 1995; 72: F29-F33)

Keywords: multiple blood transfusions, preterm babies, donor exposure.

In recent years the survival of very low birthweight babies has improved due to advances in neonatal intensive care. Such infants are at a high risk of anaemia during the first few weeks of life. ${ }^{1}$ The causes are multifactorial and include iatrogenic blood loss due to sampling and low concentrations of erythropoeitin. ${ }^{2}$ Many preterm infants, particularly those of less than 30 weeks' gestation require multiple small volume top-up transfusions. ${ }^{3}$ It has been traditional to use fresh blood ( $<$ seven days) in the United Kingdom, ${ }^{45}$ but this has given rise to high donor exposure, typically up to eight to 10 different donors, ${ }^{6}$ and generates concerns about transfusion transmitted infection (TTI). Concerns about TTI in adults and the need to reduce donor exposure have resulted in the increased use of autologous transfusion, ${ }^{7}$ yet preterm infants, most of whom have a normal life expectancy, cannot be protected in this way.

Several studies have shown no deleterious effects from transfusion of stored blood for neonatal top-ups with regard to plasma haemoglobin, ${ }^{8}$ hyperkalaemia, haematocrit, unconjugated bilirubin, $\mathrm{pH}$ and bicarbonate and $2,3-D \mathrm{PG}^{9} 10$ and we therefore decided to change our policy for neonatal top-up transfusions and to use each donation up to its full expiry date, to reduce donor exposure. At the same time we prepared an information sheet for concerned parents, outlining our efforts to minimise donor exposure and giving a detailed explanation of the contraindications to directed parental donations. ${ }^{11} \mathrm{We}$ present the results of this change in practice, together with a retrospective analysis of neonatal transfusions during the preceding 16 months.

\section{Methods}

A retrospective analysis of all blood transfusions given in the neonatal intensive care unit (NICU) between January 1991 and April 1992 was carried out from examination of case notes and laboratory documentation. From June 1992 infants admitted to the NICU and considered likely to require multiple transfusions were transfused according to a new policy, which, for ease of communication between NICU staff and the Blood Transfusion Laboratory, was called the 'BBB' (banked baby blood) scheme. All infants of $\leqslant 30$ weeks' gestational age and any others thought likely to require multiple transfusions were allocated to the 'BBB' scheme.

PREVIOUS TRANSFUSION POLICY

Plasma reduced, CMV antibody negative, $\mathrm{Rh} \mathrm{D}$ negative blood was obtained from the North London Blood Transfusion Centre (NLBTC) and used within five days of donation. The blood was supplied as quad packs - that is, a main unit with four empty satellite packs, allowing up to five separate transfusions to be given. Each satellite pack was filtered in the transfusion laboratory immediately before issue, using a Blood Component Infusion Set (Baxter Healthcare Ltd) incorporating a $170 \mu \mathrm{m}$ filter. One or two infants received more than one transfusion for a single donation but this was the exception rather than the rule because of our policy to use blood under five days old.

\section{'BBB' SCHEME}

Cord samples and maternal serum from all infants of $\leqslant 30$ weeks' gestation were sent to the Blood Transfusion Laboratory from the delivery suite for $\mathrm{ABO}$ and $\mathrm{Rh} \mathrm{D}$ grouping and 
Table 1 Distribution of transfusion requirements according to gestational age

\begin{tabular}{lllllllr}
\hline \multicolumn{7}{l}{ No of transfusions given } \\
\cline { 2 - 8 } Gestational age & 1 & 2 & 3 & 4 & 5 & $>5$ \\
\hline Retrospective analysis $(n=64):$ & 21 & 7 & 10 & 4 & 8 & 14 \\
$\leqslant 30$ weeks & 14 & 5 & 9 & 3 & 7 & 13 \\
$>30$ weeks & 7 & 2 & 1 & 1 & 1 & 1 \\
'BBB' scheme $(n=32):$ & 3 & 8 & 2 & 3 & 4 & 12 \\
$\leqslant 30$ weeks & 0 & 7 & 2 & 3 & 4 & 12 \\
$>30$ weeks & 3 & 1 & 0 & 0 & 0 & 0 \\
\hline
\end{tabular}

maternal antibody screening. Maternal serum was stored at $-30^{\circ} \mathrm{C}$. When blood was requested, a quad pack of less than five days old, plasma reduced, CMV antibody negative blood of the infant's ABO and Rh D group was ordered from the NLBTC. This was leucocyte depleted (mean leucocyte count $2 \times 10^{6} /$ unit after filtration) by the NLBTC using a Sepacell R-500 filter (Kimal Scientific Products Ltd) in conjunction with a Sterile Connecting Device (Haemonetics (UK) Ltd) to preserve the 35 day shelf life. Red cell compatibility testing was done using maternal serum and the donation was labelled and kept in reserve for that particular baby with instructions to use up to a 21 day expiry date. Whenever transfusion was required, an appropriate volume was transferred into a satellite bag and supplied without further compatibility testing. At 21 days the expiry date of unused blood was either extended to 35 days or the blood was released to stock. This decision was based either on the likelihood of further transfusions within the next 14 days or on the clinical condition of the infant.

In very low birthweight babies of $<1500 \mathrm{~g}$ receiving neonatal intensive care, the haemoglobin was monitored daily during the first 10 days of life. Top-up transfusions were given when the iatrogenic blood loss approached $7-10 \%$ of the infant's estimated blood volume or, in ventilated infants, when the haemoglobin fell below $120 \mathrm{~g} / \mathrm{l}$. Thereafter, top-up transfusions were given for symptomatic anaemia or when the haemoglobin fell below $80 \mathrm{~g} / 1$ with a reticulocyte count of $<4 \%$. The volume transfused was usually $15 \mathrm{ml} / \mathrm{kg}$. The packed cell volume of donor blood was not routinely measured and, in practice, the rise in haemoglobin varied from $10-30 \mathrm{~g} / \mathrm{l}$.

Rather than use the Blood Component Infusion Set, which has a relatively large dead space in comparison with the volume of blood issued in a satellite pack, blood was drawn up from the satellite pack into a syringe through an Alpha Micron-20 transfusion filter (Alpha Therapeutic UK Ltd), immediately before transfusion. Transfusions were given over about three hours via a syringe pump (IVAC SP 700, Graseby MS16A, or Graseby 3100).

Table 2 Donor exposure in infants who received two or more blood transfusions

\begin{tabular}{llrllll}
\hline & \multicolumn{7}{l}{ No of donors } \\
\cline { 2 - 7 } Infants & 1 & 2 & 3 & 4 & 5 & $>5$ \\
\hline $\begin{array}{l}\text { Retrospective analysis }(\mathrm{n}=43) \\
\text { 'BBB' scheme }(\mathrm{n}=29)\end{array}$ & 3 & 7 & 9 & 5 & 7 & 12 \\
& 9 & 13 & 6 & 0 & 1 & 0 \\
\hline
\end{tabular}

Routine nursing observations of heart and respiratory rates and temperature were carried out hourly during transfusion and four hourly thereafter, together with continuous ECG monitoring.

Plasma potassium was measured before and after transfusion whenever possible, ideally within four hours, when blood sampling was being performed as part of routine clinical care. Extracellular potassium in stored blood was measured by flame photometry on samples taken from satellite packs returned to the laboratory after transfusion.

Mean (SD) values are given; median values are given with ranges.

\section{Results}

RETROSPECTIVE ANALYSIS

Clinical data

Of 64 infants transfused in the NICU, 43 received more than one transfusion. Their median gestational age was 27 weeks (23-37 weeks) and median birth weight $875 \mathrm{~g}$ (495-1930 g).

\section{Transfusions}

The 43 infants who were given multiple transfusions received a total of 238 transfusions with a median of three (two to 22) and mean of $5.6(4.0)$ per infant. Transfusions were required over periods of two to 129 days. The mean interval between transfusions was $6 \cdot 4$ days. Infants of $\leqslant 30$ weeks' gestation were more likely to receive multiple transfusions than more mature infants (table 1).

\section{Donor exposure}

The infants who received multiple transfusions were exposed to a total of 210 donors. The median donor exposure was four (one to 18 ) and mean $4.9(3.5)$ per infant. Sixteen $(37 \%)$ babies had two transfusions from the same donation but no infant had more than two transfusions from the same donation.

\section{'BBB' SCHEME}

Clinical data

Since our change in policy 45 infants have received blood transfusions on the NICU up to April 1993. Thirty two were entered into the 'BBB' scheme. Of these, only three received a single transfusion and they were all of $>30$ weeks' gestation. The 29 infants who received multiple transfusions had a median gestational age of 28 weeks (24-31 weeks). Their median birth weight was $1012 \mathrm{~g}$ (565-1710 g).

\section{Transfusions}

The 29 infants who had multiple transfusions received a total of 154 transfusions, with a median of four (two to 12) and mean of 5.3 (3.1) per infant. Transfusions were required over periods of two to 70 days. The mean interval between transfusions was $6 \cdot 7$ days. All 

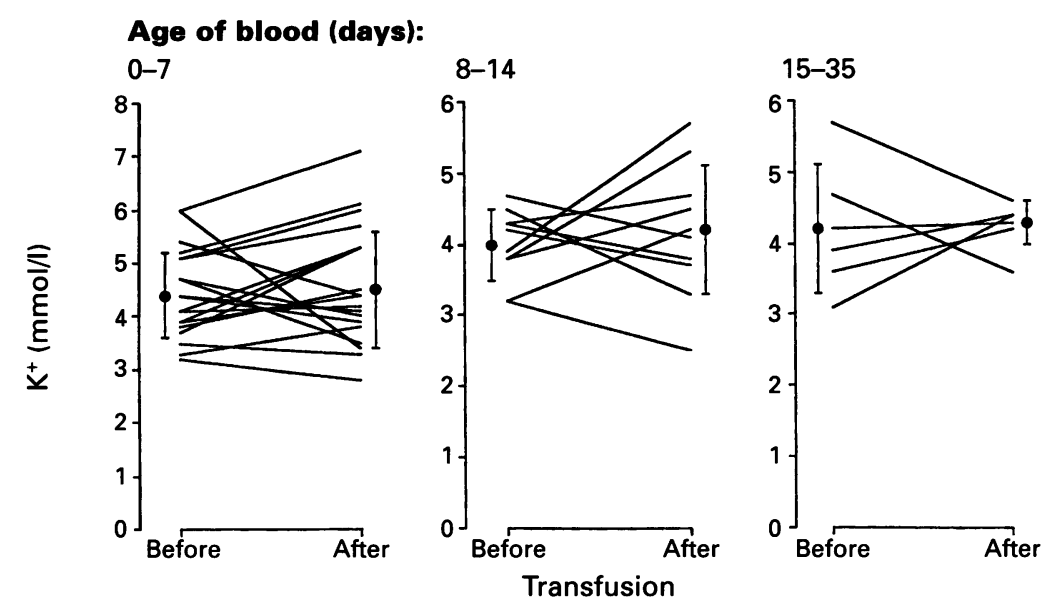

Figure 1 Changes in plasma potassium concentrations after transfusion of stored blood. Closed circles and bars indicate mean (SD).

infants of gestational age of $\leqslant 30$ weeks required multiple transfusions (table 1 ).

\section{Donor exposure}

The infants who received multiple transfusions were exposed to a total of 58 donors. The median exposure was two (one to five) per infant and mean was $2.0(0.9)$ per infant (table $2)$.' Thirteen infants were exposed to two donors; the use of a second donation was unavoidable in seven because blood was required after the first unit had expired. In three a fresh unit was ordered at 21 days, although further transfusions from the same donation could have been given, because we were initially cautious about using blood stored for $>21$ days in very sick infants. Six infants (birth weights 705-1100 g) were exposed to three donors. They received 12, 10, eight, six, six, and five transfusions over periods of 39 , $51,70,23,68$, and 63 days, respectively.

\section{Age of transfused red cells}

All babies who were entered into the 'BBB' scheme received their first transfusion with blood less than seven days old and $48 \%$ of all the transfusions actually given in the BBB scheme were with blood less than seven days old. Fifteen $(48 \%)$ of the infants who required multiple transfusions received blood that had been stored for more than 21 days.

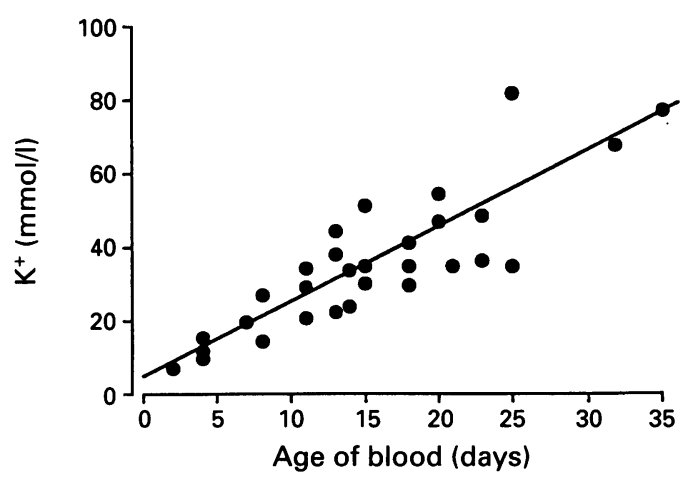

Figure 2 Rise in extracellular potassium in stored blood.
Clinical evaluation

There were no adverse clinical effects attributable to blood transfusion.

\section{Potassium measurements}

Potassium concentrations before and after transfusion, are shown in fig 1 . The maximum rise in plasma potassium of 1.8 (from 3.9 to $5.7) \mathrm{mmol} / \mathrm{l}$ occurred after the transfusion of 10 day old blood. Three babies had plasma potassium concentrations in excess of 5.5 $\mathrm{mmol} / \mathrm{l}$ before transfusion. In one baby with acute renal failure secondary to severe hypoxaemia, the potassium rose from 6.0 to 7.0 $\mathrm{mmol} / \mathrm{l}$ following transfusion of five day old blood. In the other two infants falls in plasma potassium were recorded from 6.0 to 4.7 and 5.7 to $4.7 \mathrm{mmol} / \mathrm{l}$ following transfusions of five day and 26 day old blood, respectively. Extracellular potassium concentrations were measured in blood from 30 satellite packs stored from two to 35 days. They rose steadily from $12 \mathrm{mmol} / \mathrm{l}$ at five days to values as high as $60-80 \mathrm{mmol} / \mathrm{l}$ at 35 days (fig 2 ).

Thirteen infants were not entered into the 'BBB' scheme. Nine were not allocated because they were $>30$ weeks' gestational age and subsequently required only a single transfusion. The remaining four were inadvertently omitted from the scheme; one had only a single transfusion and the other three each received two transfusions.

\section{Discussion}

Our results show that a simple change in the policy for neonatal top-up transfusions in very low birthweight babies can reduce donor exposure considerably in infants who need multiple transfusions. It is very easily implemented in a busy hospital blood transfusion laboratory, is without obvious adverse clinical effects, and supports recent recommendations issued by the British Committee for Standards in Haematology Blood Transfusion Task Force. ${ }^{12}$

It is good preventive medicine to reduce donor exposure in this group of patients because they are more likely to show the adverse effects of TTI in the long term than adults (where up to $30 \%$ of all transfused blood is given to recipients who die from their primary disease within five years. ${ }^{13}$ Several strategies have been used to reduce donor exposure in premature babies, including the use of a limited panel of 'walking donors'14 and directed donations from relatives and friends. ${ }^{11}$ The use of 'walking donors' cannot be condoned because mandatory pretransfusion testing cannot be undertaken. The arguments for and against directed donation have been extensively debated in North America ${ }^{1516}$; it certainly reduces donor exposure but has not been shown to be safer than voluntarily donated blood. ${ }^{17}$ Directed donations from parents may lead to transfusion associated graft versus host disease, unless irradiated. ${ }^{11}$ The system we describe has the advantages of a very limited donor exposure 
and the use of voluntarily donated blood which is screened comprehensively for infectious agents.

Although blood of the same $\mathrm{Rh} \mathrm{D}$ group as the infant was used in our original study, we now use $\mathrm{Rh} \mathrm{D}$ negative blood for all neonatal transfusions. This is now routinely supplied by the NLBTC for ease of administration and to cut down wastage, as units with seven satellite bags (allowing up to eight transfusions from the same donation). The use of these multisatellite packs, together with our new scheme, and a relaxation in our initially cautious 21 day reordering policy could in theory have reduced donor exposure even more. Only one of the 29 multitransfused infants would have been exposed to more than two donors.

Our results support studies from outside the United Kingdom which have shown that there is little risk to infants from the use of stored blood for small volume top-up transfusions. ${ }^{89}$ Concerns about plasma potassium are frequently cited as a justification for the use of fresh blood and have been the subject of some debate. ${ }^{18}$ The high concentrations of extracellular potassium in stored blood found in this study - up to $80 \mathrm{mmol} / \mathrm{l}$ - are in keeping with other published data ${ }^{19}$ and although they may seem rather alarming, on closer inspection the concerns about the risk of hyperkalaemia are unfounded. The theoretical risk of hyperkalaemia after a top-up transfusion is negligible because a transfusion of $15 \mathrm{ml} / \mathrm{kg}$ results in an infusion of a maximum of 0.4 $\mathrm{mmol} \mathrm{K}+/ \mathrm{kg}$ over three hours (assuming a haematocrit of $66 \%$ and $[\mathrm{K}+]$ of $80 \mathrm{mmol} / 1$ in transfused blood). This is a fraction of the infant's daily requirement of $2-3 \mathrm{mmol} / \mathrm{kg}$. ${ }^{6}$ Rarely, a baby may require multiple transfusions over a short period of time and the potassium load may then need to be considered. In vivo measurements have failed to show significant increases in posttransfusion plasma potassium after the transfusion of stored blood. On the contrary, in a few cases transfusion had the opposite effect and caused a fall in plasma potassium, as observed by others, ${ }^{9}$ who attributed it to the uptake of potassium by transfused cells which have intracellular potassium depletion. Furthermore, concerns about low values of 2,3-DPG in stored blood are also unfounded as the p50 of a premature neonate resembles that of 21 day old blood ${ }^{6}$ and 2,3-DPG is regenerated within hours of transfusion. ${ }^{10}$

Microaggregate formation in blood increases with storage. ${ }^{20}$ Its importance in very low birthweight babies is unclear but is of concern because microaggregates are probably removed in the pulmonary vasculature. ${ }^{20}$ There is some evidence that granulocytes are involved in microaggregate formation and, although the need to leucocyte-deplete blood for neonatal transfusions has not been established, ${ }^{21}$ we decided to err on the side of caution and to deplete blood within five days of donation. The use of an Alpha Micron-20 filter, which has a pore size of only $20 \mu \mathrm{m}$, immediately before transfusion probably also removes any residual microaggregates. Leucocyte depletion may also reduce further the likelihood of transmission of cell associated viruses such as HTLV-1 in this particularly susceptible group of recipients. ${ }^{22}$

There is considerable optimism about the use of rHuEPO to prevent anaemia in premature babies, but two points need to be borne in mind. Firstly, the benefit of rHuEPO in very premature babies has not been clearly established ${ }^{23-28}$ and, secondly, even if rHuEPO is shown to be effective it probably takes two to three weeks to produce major benefit. ${ }^{242829}$ Nineteen of the 29 multitransfused infants needed transfusions within the first 14 days and would still have received an average of $3 \cdot 7(1 \cdot 8)$ transfusions (range two to seven) each. rHuEPO was not used in the babies in this study, but even if it had been, the need to limit donor exposure remains very important.

This report provides further evidence to support the view that blood can be used up to the 35 day expiry date for top-up transfusions in preterm infants. The routine use of 'fresh' blood with the consequent high donor exposure is therefore difficult to justify and we advocate a change to this safer method.

We are very grateful to $\operatorname{Dr} M$ Contreras for helpful discussion and criticism.

Wardrop CAJ, Holland BM, Veale KEA. Nonphysiological anemia of prematurity. Arch Dis Child 1978; 53: 855-60. Shannon KM, Naylon GS, Torkildson JC. Circulating erythroid progenitors in the anemia of prematurity. $N$ Engl Med 1987; 317: 728-33.

3 Brown MS, Berman ER, Luckey D. Prediction of the need for transfusion during anemia of prematurity. $\mathcal{F}$ Pediatr 1990; 116: 773-8.

4 Scanlon JW, Krakaur R. Hyperkalemia following exchange transfusion. $\mathcal{F}$ Pediatr 1980; 96: 108-10.

5 DoH. Handbook of Transfusion Medicine. London: HMSO, 1989.

6 Strauss RG, Sacher RA, Blazina JF. Commentary on smallvolume red cell transfusions for neonatal patients. Transfusion 1990; 30: 565-70.

7 Anonymous. Risks and uses of donated blood. Drug and Therapeutics Bulletin 1993; 31: 89-92.

8 Humphrey MJ, Harrell-Bean HA, Eskelson C, Corrigan JJ. Blood transfusion in the neonate: effects of dilution and age of the blood on haemolysis. Clinical and Laboratory Obstetrics 1982; 101: 605-7.

9 Patten E, Robbins M, Vincent J, Richardson J, Hokanson J. Use of red blood cells older than five days for neonatal transfusion. F Perinatol 1991; 11: 37-40.

10 Delivoria-Papadopoulis M, Marrow G, Oski FA, Cohen R $O$ 'Neal P. Exchange transfusion of the newborn infan with fresh and 'old' blood: the role of storage on 2,3 diphosphoglycerate, hemoglobin-oxygen affinity, and oxygen release. $\mathcal{F}$ Pediatr $1971 ; 70$ : 898-903.

11 Strauss RG, Barnes A, Blanchette VS, Butch SH, Hume HA. Directed and limited-exposure blood donations for infants and children. Transfusion 1990; 30: 68-72.

12 British Committee For Standards In Haematology Blood Transfusion Task Force. Guidelines for administration of blood products: transfusion of infants and neonates. Transfusion Med 1994; 4: 63-9.

13 Whyte GS. The transfused population of Canterbury, New Zealand, and its mortality. Vox Sang 1988; 54: 65-70.

14 Blankenship WJ, Goetzman BW, Gross S, Hattersley PG. A walking donor program for an intensive care nursery. $\mathcal{f}$ Pediatr 1975; 86: 583-6.

15 Goldfinger D. Directed blood donations: Pro. Transfusion 1989; 29: 70-4.

16 Page PL. Directed blood donations: Con. Transfusion 1989; 29: $65-70$.

17 Starkey JM, MacPherson JL, Bolgiano DC, Simon ER, Zuck TF, Sayers MH. Markers for transfusion-transmit ted disease in different groups of blood donors. $\mathscr{J} A M A$ ted disease in different

18 Strauss RG. Routinely washing irradiated red cells before transfusion seems unwarranted. Transfusion 1990; 30: 675-7.

19 Seghatchian MJ, Vickers M, Ip AH, Stivala JF, deSilva PM The potassium, haemoglobin and acid content of CPDA-1 whole blood, plasma-reduced red cells and red cells suspended in SAG-M over 35 days. Transfusion Med 1993; 3 (suppl 2): 58. 
20 Snyder EL, Bookbinder M. Role of microaggregate blood inical medicine. Transfusion 1983; 23: 460-70

21 Strauss RG. Selection of white cell-reduced blood components for transfusion during early infancy. Transfusion 1993; 33: 352-7.

22 DePalma L, Luban NLC. Transmission of human T-lymphotrophic virus type I infection to a neonatal infant by transfusion of washed and irradiated cells. Transfusio 1993; 33: 582-4.

23 Christensen RD. Recombinant erythropoietic growth factors as an alternative to erythrocyte transfusion for patients with 'anemia of prematurity'. Pediatrics 1989; 83: 793-6.

24 Carnielli V, Mintini G, Da Riol R, Dall'Amico $R$ Cantarutti F. Effect of high doses of human recombinan erythropoietin on the need for blood transfusions in preterm infants. $f$ Pediatr 1992; 121: 98-102.

25 Shannon KM, Mentzer WC, Abels RI. Recombinant human erythropoietin in the anaemia of prematurity: results of a placebo controlled pilot study. $\mathcal{F}$ Pediatr 1991; 118: 949-55.

26 Halperin DS, Wacker P, Lacourt G. Effect of recombinant Human erythropoietin in infants with the anaemia of prematurity: a pilot study. $\mathcal{f}$ Pediatr 1990; 116: 779-86.

27 Obladen M, Maier R, Grauel L. Recombinant human erythropoietin (rHuEPO) for prevention of anaemias of prematurity: a randomized multicentre trial. Pediatr Res 1990; 28 (suppl): 287A.

28 Maier RF, Obladen M, Scigalla P, Linderkemp O, Duc G, Hieronimi $G$, et al. The effect of Epoietin Beta (recombinant human erythropoietin) on the need for transfusion in very-low-birthweight infants. $N$ Engl f Med 1994; 330: 1173-8.

29 Emmerson A. Role of erythropoietin in the newborn. Arch Dis Child 1993; 69: 273-5. 